\title{
SPORT PSYCHOLOGICAL SKILLS TRAINING AND PSYCHOLOGICAL WELL-BEING
}

\author{
David J. EDWARDS \& Ben J.M. STEYN \\ Department of Biokinetics, Sport and Leisure Sciences, University of Pretoria, Pretoria, \\ Republic of South Africa
}

\begin{abstract}
The impact of psychological skills training (PST) package programs on life, health, well-being in general and South African youth in particular has been relatively neglected. For example, prior to this research the impact of PST on the core health component of psychological well-being had not been evaluated, nor had the conceptual and/or empirical relationship between psychological skills and psychological well-being been investigated. While PST is often conducted individually due to its personal and specific nature, group training should not be overlooked especially in South Africa where community interventions are an important part of health promotion. With the above considerations in mind a triangulated design involving individual, group and community interventions, as well as elite and expert case studies was utilized to evaluate the effectiveness of a PST program and to investigate the relationship between psychological skills and psychological well-being. Results based on quantitative and qualitative outcome and process measurements indicated general improvement in psychological skills, psychological well-being and sporting performance. Psychological skills and psychological well-being were found to be interrelated concepts, with overlapping components. Recommendations for ongoing and future research at individual, group and community level are made.
\end{abstract}

Key words: Psychological skills training; Psychological well-being; Sporting performance.

\section{INTRODUCTION}

Psychological skills training (PST) refers to the enhancement of naturally occurring everyday activities and competencies, in relation to specific settings such as sport and exercise (Weinberg \& Gould, 2007). In themselves the skills are distinct yet interrelated components, separated for research and training purposes. Early PST interventions trained single skills such as physiological arousal, cognitive arousal, mental imagery, attention, concentration, selfconfidence, goal setting and motivation. Over the last twenty years PST package programs, which train a variety of psychological skills have been developed, implemented and evaluated (Wann \& Church, 1998). These PST programs which appear to provide optimum psychological skills training (MacDougall et al., 2001), have been extensively utilized by overseas elite and non-elite, youth and adult sportspeople (Sanchez \& Lesyk, 2001), and are adapted to suit the individuals and/or groups receiving the program. Broad base PST programs have special value for youth athletes in their inclusion of biological, social and spiritual components, which can improve general life skills and development. Because of the greater level of in-depth training, which occurs during PST package programs, it is logical to deduce 
that PST programs have a different impact on psychological well-being than single PST interventions. However the impact of PST programs on psychological well-being as well as the conceptual and empirical relationship between psychological skills and psychological well-being have not been researched, with only one study alluding to the relationship between these two concepts (Kirschenbaum et al., 1995). One fundamental link is that both psychological skills and psychological well-being are trainable psychological concepts, essential for health and performance in sport and in general life.

Psychological well-being has undergone extensive empirical review and evaluation over the last two decades (Wissing \& Van Eeden, 1998). Theoretically and conceptually grounded on the work of researchers such as Gordon Allport (1961), Charlotte Buhler (1935), Marie Jahoda (1958), Carl Jung (1933), Erik Erikson (1959), Abraham Maslow (1968), Bernice Neugarten (1973) and Carl Rogers (1961), as well as additional more meaningful connotations of 'eudemonia', such as realizing potential through some form of struggle, Ryff's (1989) research has brought about a shift in focus from a subjective to an objective conception of psychological well-being. This has resulted in a new objective psychological well-being measurement being developed (Ryff, 1989; Ryff \& Keyes, 1995), with the following components: autonomy, personal growth, environmental mastery, purpose in life, positive relations with others and self-acceptance. When unpacked, these components and psychological skill components of arousal, mental imagery attention and concentration, selfconfidence, goal setting and motivation, appear to overlap.

Sport psychology in South Africa is a developing area (Witton, 2004). PST programs are seldomly conducted with adult elite athletes and generally not available to local youth athletes. An extensive review revealed only one recent local published article on the implementation and evaluation of a PST program (Pieterse \& Potgieter, 2006). Further PST programs need to be utilized to improve sport and promote development, especially for youth. PST programs should not only be implemented individually, but also in group settings as there is a wealth of rich culturally diverse knowledge in South Africa, which needs to be shared. Support groups also improve psychological well-being (Mthembu, 2001; Rappaport, 1985). Utilized singly or together with existing interventions, PST programs have enormous potential as community health intervention strategies.

\begin{abstract}
AIM
The first aim of the research was to implement a PST program for youth track athletes, assessing its impact on psychological skills, psychological well-being and performance, in an individual and group context. The second was to evaluate its usefulness as a community workshop. The third aim was to implement the PST program with adult elite participants to assess its effectiveness and externally validate the program. The fourth was to acquire sport psychology experts' views on the relationship between psychological skills and psychological well-being.
\end{abstract}

\title{
HYPOTHESES
}

It was expected that the PST program would improve the experimental group's psychological skills, psychological well-being and performance in comparison to a school control group. It was estimated that the PST program would enhance a community workshop intervention 
groups' psychological skills. It was expected that the PST program would improve adult elite athletes' psychological skills and psychological well-being. It was anticipated that the concepts and components of psychological skills and psychological well-being would be interrelated in various ways.

\section{METHOD}

\section{Design}

A triangulated design, involving individual, group and community interventions, as well as adult elite and expert case studies, was utilized.

\section{PST program}

The PST program was based on Wann \& Church's (1998) program for college track athletes, which incorporated most of the usual sport psychology theory, skills and training techniques. In addition the research of Beck (1976), Bull et al. (1996), Carpenter (1894), Dweck (1999, 2005), Ellis (1962), Hanin (1997), Harris and Harris (1984), Harwood et al. (2004), Jacobson (1929), Jennings (1993), Lane et al. (2001), Lang (1979), Martens et al. (1990), Meichenbaum, (1985), Moran (2004), Nideffer (1985), Sacket (1934), Sheldon and Eccles (2005), Watson and Nesti (2005), Weinberg and Gould (2007) as well as Yerkes and Dodson (1908) all contributed to the development of the present PST program, which included the following psychological skills: physiological arousal, cognitive arousal, mental imagery, attention, concentration, self-confidence, goal setting and motivation.

Each session covered sport psychological skill theory and practice. Some skills were combined for convenience and didactic purposes, namely attention and concentration, and goal setting and motivation. Physiological arousal training used breathing and progressive relaxation techniques in relation to the inverted $U$ hypothesis and zone of optimal functioning theory. Cognitive arousal training was concerned with the A-B-C model of event reaction, using thought stopping and positive self-talk. Mental imagery training covered vividness, meaning and breathing related to internal and external imagery. Attention and concentration training incorporated direction, focus, eye control, cue words, thought stopping and positive self-talk. Self-confidence training focused on the Yerks-Dodson Law, optimum selfconfidence and confidence maintenance. Goal setting and motivation training covered short and long-term, process, performance, outcome goals, internal and external locus of control, as well as entity and incremental learning perspectives. Handouts and homework were explained and provided on each psychological skill. The program was adapted to suit youth and adult, individual, group and community contexts, school, workshop and adult elite participants.

\section{School group intervention}

The school group intervention included a quasi-experimental design. The sample consisted of 16 female 100 metre track athletes, between the ages of 16 and 18 years. This event was chosen because it could be measured quantitatively. Eight weeks before the athletic season nine experimental and seven control group participants were assessed using qualitative and qualitative outcome measures. Daily training schedules were provided to the participants in order to acquire in-depth knowledge. The experimental group received the PST program over a six session, six week period with different psychological skills covered in each session. 
Process measures assessed the effectiveness of each session. Learners were able to form a supportive group environment amplifying the meaning of the program into one of learning skills for life and health as well as athletic performance. Such a transfer of training effect augers well for the future of PST programs in general. After the six week program the experimental and control group participants were re-assessed using the outcome measures. A review session was conducted with the experimental group participants, during the athletics season. Following follow-up testing, the control group then received the PST program, run in the same manner as with the experimental group. Some data were excluded due to nonattendance.

\section{Community workshop intervention}

The PST program was conducted as a workshop at a health and fitness seminar. The program covered the PST theory and techniques over an hour and a half session. Five participants (including athletes, dancers and gym members) completed the pre- and post-session psychological assessment. A supportive group environment was formed and diverse knowledge sharing occurred.

\section{Adult elite athletes case study}

A male cricket player and female swimmer, who had represented their province and country, both 27-years-old, participated in the study. For qualitative research purposes these participants were chosen on the basis of their established relationship with the researcher, experience in youth sport, sport psychology understanding, insight into and willingness to discuss their psychological skills training experiences. The six psychological skills were trained over three weekends. Outcome pre-, post- and follow-up, as well as process assessments were completed. Owing to their sport and exercise experience, in-depth discussions and valuable knowledge sharing occurred.

\section{Sport psychology expert case study}

Five experts comprised of local and international sport psychologists were asked to comment on the relationship between psychological skills and psychological well-being. All experts were known to the researcher, had extensive qualifications, expertise, research and practical experience in the area of sport psychology.

\section{Measuring instruments}

\section{Ryff's psychological well-being scale}

Ryff's (1989) standardized psychological well-being scale was used as an outcome measure to assess the school group intervention and adult elite participants (at pre-, post and follow-up testing) on the six dimensions of psychological well-being: autonomy, personal growth, environmental mastery, purpose in life, positive relations with others and self-acceptance. The scale was initially constructed as a twenty item questionnaire and has been standardised in 3,9 and 14-item forms. The 3-item version was used in this research. During initial assessment construction, the Cronbach alpha coefficients of participants for the twenty item scale were high: autonomy .88 , personal growth .81 , environmental mastery .81 , purpose in life .82 , positive relations with others .83 and self-acceptance .85 (Ryff, 1989). 


\section{Bull's mental skills questionnaire}

Bull's mental skills questionnaire was used as an outcome measure to assess the school group, adult elite (at the pre-, post and follow-up test) and community workshop intervention participants on psychological skills. The questionnaire measures: imagery, mental preparation (goal setting), self-confidence, anxiety and worry management, concentration, relaxation and motivation (Bull et al., 1996). The scale has been translated into Dutch and shown to have generally high Cronbach alpha levels of $.80, .64, .62, .61, .59, .72$ and .72 for the six subscales (Snauwaert, 2001).

\section{Time measurement}

As the third outcome measure the school group intervention participants' speed in seconds, over their track distance (100 metres), was measured at pre-, post- and follow-up testing.

\section{Qualitative outcome measures}

Each school group intervention participant and adult elite sportsperson (at the pre-, post and/or follow-up test) described their understanding of psychological well-being and psychological skills training. At post-test they described their experience of autonomy, personal growth, environmental mastery, purpose in life, positive relations with others and self-acceptance since pre-testing. Following the PST program the school group experimental participants were asked to describe their experience of being in the group. After the intervention participants assessed the PST program by completing the following questions: How did you experience the program? What did you appreciate about the program? How did you think the program could be improved?

\section{Relaxation measures}

The relaxation measures of heart rate and number of breaths per minute were used as a process measure before and after the physiological arousal session.

\section{Competitive State Anxiety Inventory 2 (CSAI-2)}

Martens et al. (1990) Competitive State Anxiety Inventory-2, was used as a before and after session process measure to assess physiological, cognitive arousal and self-confidence. It has three subscales: cognitive anxiety, somatic anxiety and self-confidence. The reliability of the three subscales is high, ranging between .79 and .90 . High Cronbach alphas of between .79 to .83 for cognitive anxiety, .82 to .83 for somatic anxiety and .87 to .90 for self-confidence were found during assessment construction (Martens et al., 1990).

\section{Sports imagery questionnaire (SIQ)}

Hall et al. (1998) sports imagery questionnaire was used as a before and after session process measure to assess mental imagery ability. It has thirty items with five subscales, which are motivational specific, motivational general-mastery, motivational general-arousal, cognitive specific and cognitive general. Initial assessment during questionnaire construction revealed high Cronbach alpha levels for the five subscales of $.88, .83, .70, .85$ and .75 respectively (Hall et al., 1998). 


\section{Concentration grid}

A concentration grid was used as a before and after session process measure to assess attention and concentration. The block grid design contains digits ranging from 1 to 99 , scrambled in the grid. The participants' time to acquire numbers, 0 to 49 (pre-session) and 5099 (post-session), was measured. Concentration grids have been used at length in Eastern Europe (Weinberg \& Gould, 2007).

\section{Perception of success questionnaire (POSQ)}

Roberts et al. (1998) POSQ (adult version) was used as a before and after session process measure to assess goal setting and motivation. The scale assesses both ego and task orientation. It is a twelve-item questionnaire with 6 ego and 6 task questions (Moran, 2004). The scale has high internal reliability for the orientations, with high alpha coefficients of .98 for task orientation and .97 for ego orientation, and inter-orientation correlation of .08 (Roberts et al., 1998).

\section{Self-theory questionnaire}

Dweck's 3 and 8-item self-theory questionnaires assess entity and incremental theory (Dweck, 1999). Two separate validation studies on the 3- and 8-item questionnaires revealed correlational coefficient values ranging between .83 and .92 (Levy et al., 1998). The research of Biddle et al. (2003) revealed high Cronbach alphas of .74 for entity and .80 incremental theory questions. The 3-item applied sport setting scale was used as a before and after session process measure to assess motivational aspects of entity and incremental theory.

\section{Qualitative process measures}

The school group intervention participants were provided with a diary to keep a detailed record of their training, learning experiences and emotions per week over the season. Before and after each session the school group intervention participants and adult elite sportspeople were asked to complete what the psychological skill (depending on the session either physical arousal, cognitive arousal, mental imagery, attention, concentrations, self-confidence, goal setting and motivation) meant to them. After each session the school group intervention and adult elite participants were asked to describe their experience of the session.

\section{Data analysis}

Quantitative data were analyzed using non-parametric statistics. Qualitative data were analyzed using content analysis.

\section{RESULTS AND DISCUSSION}

Results are divided into intervention and case study sections. In the following tables Bull's mental skills questionnaire subscales are coded as follows: imagery ability (ia), mental preparation (mp), self-confidence (sc), anxiety and worry management (awm), concentration ability (ca), relaxation ability (ra) and motivation (m). Ryff's psychological well-being subscales are coded in the following manner: autonomy (au), personal growth (pg), environmental mastery $(\mathrm{em})$, purpose in life $(\mathrm{pl})$, positive relations with others (pr) and selfacceptance (sa). The process quantitative measures are coded as follows: physiological arousal 
measure of heart rate (pha1), breaths per minute (pha2), CSAI-2 somatic anxiety subscale (pha3), CSAI-2 cognitive anxiety subscale (ca), SIQ (im), concentration grid (ac), CSAI-2 self-confidence subscale (sc), POSQ (gm1) and Self-theory Questionnaire (gm2). A decrease in pha1, pha2 and ac results in a positive improvement. The school group intervention pre-test is marked as T1, post-test as T2 and follow-up as T3. The number 1 or 2 behind the psychological well-being and mental skills questionnaire subscale codes refers to pre-test T1 (if there is a 1 behind it) or post-test T2 (if there is a 2 behind it).

\section{School intervention group}

\section{TABLE 1. PSYCHOLOGICAL SKILLS MEANS AND STANDARD DEVIATIONS (COMPARATIVE DATA)}

\begin{tabular}{|l|l|l|l|l|l|l|l|l|}
\hline \multirow{2}{*}{ Component } & \multicolumn{3}{|c|}{ ia1 } & \multicolumn{2}{c|}{ mp1 } & \multicolumn{2}{c|}{ sc1 } & \multicolumn{2}{c|}{ awm1 } \\
\cline { 2 - 9 } & Mean & SD & Mean & SD & Mean & SD & Mean & SD \\
\hline Experimental & 19.13 & 2.95 & 15.00 & 2.27 & 19.25 & 2.66 & 16.75 & 4.20 \\
\hline Control & 15.75 & 4.99 & 17.75 & 6.24 & 18.75 & 2.06 & 17.50 & 1.29 \\
\hline Component & \multicolumn{3}{|c|}{ ia2 } & \multicolumn{2}{c|}{ mp2 } & \multicolumn{2}{c|}{ sc2 } & \multicolumn{2}{c|}{ awm2 } \\
\cline { 2 - 9 } & Mean & SD & Mean & SD & Mean & SD & Mean & SD \\
\hline Experimental & 19.37 & 2.20 & 16.88 & 3.00 & 17.50 & 3.25 & 15.13 & 4.73 \\
\hline Control & 16.50 & 6.61 & 12.50 & 5.45 & 15.00 & 4.00 & 16.00 & 3.37 \\
\hline
\end{tabular}

\begin{tabular}{|l|l|l|l|l|l|l|l|l|}
\hline Component & \multicolumn{2}{|c|}{ ca1 } & \multicolumn{2}{c|}{ ra1 } & \multicolumn{2}{c|}{ m1 } & \multicolumn{2}{c|}{ msqtotal1 } \\
\hline & Mean & SD & Mean & SD & Mean & SD & Mean & SD \\
\hline Experimental & 19.63 & 4.81 & 19.13 & 3.40 & 19.63 & 2.67 & 128.50 & 14.82 \\
\hline Control & 19.25 & 2.63 & 14.25 & 4.65 & 16.75 & 4.57 & 120.00 & 18.38 \\
\hline Component & \multicolumn{3}{|c|}{ ca2 } & \multicolumn{3}{c|}{ ra2 } & \multicolumn{3}{c|}{ m2 } & \multicolumn{2}{c|}{ msqtotal2 } \\
\hline & Mean & SD & Mean & SD & Mean & SD & Mean & SD \\
\hline Experimental & 19.50 & 3.42 & 17.75 & 2.87 & 20.00 & 3.02 & 126.13 & 16.37 \\
\hline Control & 18.75 & 2.87 & 13.25 & 7.76 & 14.00 & 5.83 & 106.00 & 16.08 \\
\hline
\end{tabular}

$* \mathrm{p}<.05, * * \mathrm{p}<.01$

Table 1 refers to means and standard deviations of the eight experimental and four control group participants. Results compare pre- and post-test assessment data. Although the Mann Whitney Test revealed no asymptotic significant quantitative differences, as expected qualitative content analysis indicated general improvements in the experimental group T2 with regard to insight into the meaning of psychological skills training in comparison to pre-testing and the control group and demonstrated a holistic life skill orientation and concern with interpersonal relationships. This holistic training effect of PST has been noted in other studies (Wann \& Church, 1998). 


\section{TABLE 2. ATHLETIC PERFORMANCE TIMES AND STANDARD DEVIATIONS (COMPARATIVE DATA)}

\begin{tabular}{|l|c|c|c|c|}
\hline & \multicolumn{2}{|c|}{ T1 } & \multicolumn{2}{c|}{ T2 } \\
\hline Group & Mean & SD & Mean & SD \\
\hline Experimental & 17.15 & 1.56 & 16.98 & 0.11 \\
\hline Control & 17.16 & 3.54 & 17.50 & 1.64 \\
\hline
\end{tabular}

$* \mathrm{p}<.05, * * \mathrm{p}<.01$

Table 2 refers to the means and standard deviations of the two experimental and two control group participants who completed pre- and post-test time measurements. The Mann-Witney Test indicated no significant differences between experimental and control groups over time. Qualitative feedback suggested the PST program improved participants' athletic ability and assisted them with other sport and exercise activities. Similar impact of PST programs on sporting performance has been documented elsewhere (Harmison, 2006; Wann \& Church, 1998; Weinberg \& Gould, 2007).

$T A B L E$ 3. PSYCHOLOGICAL WELL-BEING MEANS AND STANDARD DEVIATIONS (COMPARATIVE DATA)

\begin{tabular}{|l|l|l|l|l|l|l|l|l|}
\hline \multirow{2}{*}{ Component } & \multicolumn{2}{|c|}{ au1 } & \multicolumn{2}{c|}{ pg1 } & \multicolumn{2}{c|}{ em1 } & \multicolumn{2}{c|}{ pl1 } \\
\cline { 2 - 11 } & Mean & SD & Mean & SD & Mean & SD & Mean & SD \\
\hline Experimental & 13.38 & 3.11 & 15.13 & 2.47 & 12.25 & 1.83 & 14.13 & 1.13 \\
\hline Control & 13.20 & 2.59 & 14.20 & 5.93 & 13.40 & 2.70 & 13.60 & 4.16 \\
\hline Component & \multicolumn{2}{|c|}{ au2 } & \multicolumn{2}{c|}{ pg2 } & \multicolumn{2}{c|}{ em2 } & \multicolumn{2}{c|}{ pl2 } \\
\cline { 2 - 11 } & Mean & SD & Mean & SD & Mean & SD & Mean & SD \\
\hline Experimental & 13.75 & 2.38 & 15.00 & 4.04 & 13.13 & 1.46 & 13.75 & 3.37 \\
\hline Control & 11.60 & 2.30 & 11.20 & 4.09 & 10.80 & 4.97 & 14.20 & 0.84 \\
\hline
\end{tabular}

\begin{tabular}{|l|l|l|l|l|l|l|}
\hline \multirow{2}{*}{ Component } & \multicolumn{2}{|c|}{ pr1 } & \multicolumn{2}{c|}{ sa1 } & \multicolumn{2}{c|}{ total1 } \\
\cline { 2 - 7 } & Mean & SD & Mean & SD & Mean & SD \\
\hline Experimental & 16.13 & 1.46 & 15.50 & 2.33 & 86.50 & 5.32 \\
\hline Control & 15.40 & 1.82 & 14.40 & 2.19 & 84.20 & 16.47 \\
\hline \multirow{2}{*}{ Component } & \multicolumn{3}{|c|}{ pr2 } & \multicolumn{2}{c|}{ sa2 } & \multicolumn{2}{c|}{ total2 } \\
\cline { 2 - 7 } & Mean & SD & Mean & SD & Mean & SD \\
\hline Experimental & 15.38 & 1.60 & 15.38 & 1.30 & 87.63 & 6.19 \\
\hline Control & 14.20 & 2.17 & 16.00 & 1.87 & 82.00 & 10.70 \\
\hline
\end{tabular}

$* \mathrm{p}<.05, * * \mathrm{p}<.01$

Table 3 refers to the means and standard deviations of the eight experimental and five control group participants. Results compare pre- and post-test assessment data. The Mann-Witney Test indicated no significant differences between experimental and control groups on any of the psychological well-being dimensions. At post-test, qualitative findings with regard to the meaning of psychological well-being for the experimental group indicated general growth, incorporating various mental health and psychological skill aspects, having a positive attitude and mindset in comparison to pre-test and control group. The follow-up test provided evidence 
that perceptions of psychological well-being development were being maintained. This finding realized one aim of the research and confirmed the expectation that the PST program would improve psychological well-being. In general, it attests to the value of such a program as a health intervention strategy. Discussions with participants and daily training data revealed both experimental and control group participants were competing in sports on a regular basis, therefore the variable of exercise as such could not have impacted on psychological wellbeing.

\section{TABLE 4. PSYCHOLOGICAL SKILL PROCESS MEASUREMENT MEANS AND STANDARD DEVIATIONS}

\begin{tabular}{|l|l|l|l|l|l|l|l|l|l|l|l|}
\hline \multirow{2}{*}{$\begin{array}{l}\text { Experimental } \\
\text { group }\end{array}$} & \multicolumn{2}{|c|}{ pha1 } & \multicolumn{2}{c|}{ pha2 } & \multicolumn{2}{c|}{ pha3 } & \multicolumn{2}{c|}{ ca } & \multicolumn{2}{c|}{ im } \\
\cline { 2 - 11 } & Mean & SD & Mean & SD & Mean & SD & Mean & SD & Mean & SD \\
\hline $\begin{array}{l}\text { Before } \\
\text { session }\end{array}$ & 69.63 & 17.99 & 18.50 & 6.14 & 28.63 & 5.10 & 23.38 & 4.98 & 154.75 & 16.85 \\
\hline After session & 63.25 & 21.95 & $11.38^{*}$ & 3.93 & $33.88^{*}$ & 2.47 & $31.50^{*}$ & 4.28 & $\begin{array}{l}166.13 \\
*\end{array}$ & 20.00 \\
\hline
\end{tabular}

\begin{tabular}{|l|l|l|l|l|l|l|l|l|}
\hline \multirow{2}{*}{$\begin{array}{l}\text { Experimental } \\
\text { group }\end{array}$} & \multicolumn{2}{|c|}{ ac } & \multicolumn{1}{c|}{ Sc } & \multicolumn{2}{c|}{ gm1 } & \multicolumn{3}{c|}{ gm 2 } \\
\cline { 2 - 9 } & Mean & SD & Mean & SD & Mean & SD & Mean & SD \\
\hline Before session & 486.38 & 125.91 & 26.13 & 3.87 & 41.75 & 7.94 & 31.50 & 2.88 \\
\hline After session & 395.88 & 64.34 & $30.38^{* *}$ & 3.25 & 42.50 & 8.28 & 31.38 & 3.34 \\
\hline
\end{tabular}

$* \mathrm{p}<.05, * * \mathrm{p}<.01$

Table 4 refers to the means and standard deviations of the eight experimental group participants before and after session psychological skill process measurements. Wilcoxon Signed Ranks Test indicated significance at the $1 \%$ alpha level for breaths per minute (pha2) $(\mathrm{p}=0.012)$, somatic anxiety (pha3) $(\mathrm{p}=0.018)$, cognitive anxiety $(\mathrm{ca})(\mathrm{p}=0.012)$, imagery (im) $(\mathrm{p}=0.036)$ and significance at the $5 \%$ alpha level for self-confidence $(\mathrm{sc})(\mathrm{p}=0.011)$. The qualitative before and after session evaluation, demonstrated growth in meaning on every psychological skill. Similar findings have occurred in other PST studies (MacDougall et al., 2001). 


\section{TABLE 5. CORRELATIONAL MATRIX OF PSYCHOLOGICAL WELL-BEING AND MENTAL SKILLS QUESTIONNAIRE SUBSCALES}

\begin{tabular}{|c|c|c|c|c|c|c|c|c|c|c|c|c|c|}
\hline & au & pg & em & pl & pr & sa & ia & $\mathbf{m p}$ & sc & awm & ca & ra & m \\
\hline \multicolumn{14}{|l|}{ au } \\
\hline pg & .377 & & & & & & & & & & & & \\
\hline em & .203 & .415 & & & & & & & & & & & \\
\hline pl & $.644^{*}$ & $.620^{*}$ & .355 & & & & & & & & & & \\
\hline pr & -.109 & .328 & .169 & .307 & & & & & & & & & \\
\hline sa & .088 & .447 & .255 & .332 & .198 & & & & & & & & \\
\hline ia & .239 & $.630^{*}$ & -.184 & .457 & -.031 & .053 & & & & & & & \\
\hline $\mathbf{m p}$ & .512 & .541 & .489 & $.635^{*}$ & .032 & .181 & .395 & & & & & & \\
\hline sc & -.060 & -.007 & .205 & .052 & .275 & .075 & -.292 & .100 & & & & & \\
\hline awm & -.204 & .185 & .513 & -.001 & .403 & -.019 & -.315 & -.168 & .380 & & & & \\
\hline ca & -.022 & .055 & .048 & -.303 & .047 & .122 & -.101 & .018 & .549 & .237 & & & \\
\hline ra & .300 & .291 & .169 & .435 & .447 & .009 & .060 & .070 & $.614 *$ & .514 & .236 & & \\
\hline $\mathbf{m}$ & .432 & .533 & .294 & $.554 *$ & .299 & .299 & .372 & .466 & $.660 *$ & .272 & .413 & $.821 * *$ & \\
\hline
\end{tabular}

$* \mathrm{p}<.05, * * \mathrm{p}<.01$

Table 5 refers to the correlation between the psychological well-being and mental skills questionnaire subscales. Data were collected at the pre-test assessment of the eight experimental and five control group participants. In view of the fact that the scales were independently standardized with high alpha coefficients, as was expected, psychological wellbeing components on the one hand and psychological skill components on the other were significantly positively correlated. Significant correlation at $1 \%$ alpha level was found between motivation and relaxation ability $(0.82)$. There were significant correlations at the $5 \%$ alpha level between autonomy and purpose in life (0.64), personal growth and purpose in life $(0.62)$, personal growth and imagery ability $(0.63)$, purpose in life and mental preparation (0.64), purpose in life and motivation (0.56), self-confidence and relaxation ability (0.61), and self-confidence and motivation (0.66). Participants evaluated experience of the psychological well-being components change from pre- to post-testing indicated positive relationships between autonomy and mental imagery, self-confidence as well as motivation, personal growth and physiological arousal, cognitive arousal, mental imagery as well as selfconfidence, environmental mastery and physiological arousal, cognitive arousal, mental imagery, attention as well as concentration, purpose in life and attention, concentration, selfconfidence, goal setting as well as motivation, positive relations with others and physiological arousal, self-confidence as well as motivation, and self-acceptance and physiological arousal, cognitive arousal, self-confidence as well as motivation. Results therefore empirically validate that each psychological well-being component is positively related to multiple psychological skill components and vice versa.

\section{School participants evaluation of PST program and group}

Feedback suggested school experimental group participants generally found the program to be an important component of sports training, enhancing psychological, life skills and aspects of psychological well-being, with spirituality an important component. Responses suggested: it 
was an understandable, educational experience, effective in teaching techniques using an overlapping approach. Responses to being in the PST group included: it was an interactional experience, which improved PST and understanding of other people's emotions.

\section{Community workshop intervention}

\section{TABLE 6. PSYCHOLOGICAL SKILLS MEANS AND STANDARD DEVIATIONS - WILCOXON SIGNED RANKS TEST FOR COMMUNITY WORKSHOP PARTICIPANTS $(N=5)$}

\begin{tabular}{|l|l|l|l|l|l|l|l|l|}
\hline \multirow{2}{*}{ Component } & \multicolumn{2}{|c|}{ ia } & \multicolumn{2}{c|}{ mp } & \multicolumn{2}{c|}{ sc } & \multicolumn{2}{c|}{ awm } \\
\cline { 2 - 9 } & Mean & SD & Mean & SD & Mean & SD & Mean & SD \\
\hline Pre-test & 21.60 & 2.51 & 16.80 & 6.06 & 17.80 & 6.42 & 15.60 & 6.73 \\
\hline \multirow{2}{*}{ Component } & \multicolumn{2}{|c|}{ ia } & \multicolumn{2}{c|}{$\mathbf{m p}$} & \multicolumn{2}{c|}{ sc } & \multicolumn{2}{c|}{ awm } \\
\cline { 2 - 10 } & Mean & SD & Mean & SD & Mean & SD & Mean & SD \\
\hline Post-test & 20.20 & 3.03 & 19.40 & 5.08 & 17.20 & 6.30 & 16.80 & 8.98 \\
\hline
\end{tabular}

\begin{tabular}{|l|l|l|l|l|l|l|l|l|}
\hline \multirow{2}{*}{ Component } & \multicolumn{2}{|c|}{ ca } & \multicolumn{2}{c|}{ ra } & \multicolumn{2}{c|}{ m } & \multicolumn{2}{c|}{ msqtotal } \\
\cline { 2 - 9 } & Mean & SD & Mean & SD & Mean & SD & Mean & SD \\
\hline Pre-test & 16.60 & 7.80 & 13.60 & 5.08 & 18.80 & 5.36 & 120.80 & 29.79 \\
\hline \multirow{2}{*}{ Component } & \multicolumn{2}{|c|}{ ca } & \multicolumn{2}{c|}{ ra } & \multicolumn{2}{c|}{ m } & \multicolumn{2}{c|}{ msqtotal } \\
\cline { 2 - 9 } & Mean & SD & Mean & SD & Mean & SD & Mean & SD \\
\hline Post-test & 18.80 & 6.26 & 17.40 & 5.08 & 17.80 & 5.76 & $127.60^{*}$ & 35.93 \\
\hline
\end{tabular}

$* \mathrm{p}<.05, * * \mathrm{p}<.01$

Table 6 refers to the means and standard deviations of the five workshop participants who completed pre- and post-assessment. The Wilcoxon Signed Ranks Test indicated a significance difference in overall psychological skills $(\mathrm{p}=0.042)$. While no significant change is noted with regard to any particular skill, results are in the expected direction of improvements in some of the skills. The significant improvement in overall psychological skills after an hour and a half session, displays the potential immediate effectiveness of PST programs and its value as a community intervention strategy.

\section{Adult elite athlete case studies}

Adult elite athlete case studies revealed improvement in participants' psychological skills and psychological well-being. Adult elite athlete case studies confirmed the usefulness of the program, that it was suitably packaged in terms of structure, theory, knowledge and application. Adult elite athletes' data results were in the expected direction and feedback provided external validity for the study.

\section{Sport psychology experts}

Expert responses suggested that the relationship between psychological skills and psychological well-being is dependent on how the concepts are defined and in what context, for example psychological well-being may be a psychological skill. Experts stated psychological skills are part of general life skills, trained for specific settings such as sport and exercise, usually associated more with performance outcomes than well-being, with 
spirituality an important aspect. They envisaged both correlational and causative relationships in both directions. Psychological skills can improve psychological well-being, with psychological well-being required for psychological skills to be effective. Lastly experts suggested training in psychology is important when conducting PST and that sport coaches have an integral role to play in PST.

\section{CONCLUSION}

The PST program generally improved psychological skills and psychological well-being at individual, group and community level. From a theoretical and conceptual perspective, the interventions and case studies suggested the relationship between psychological skills and psychological well-being is dependent on how and in what context the concepts are defined, and supported the notion that multiple causal and correlational relationships may exist between psychological well-being and psychological skills both in and between their respective components. Essentially both concepts are psychological variables, each necessary for health and performance. This study provides a foundation for further research related to psychological skills training and well-being. Future PST interventions should be promoted with parents, principals and sport coaches and implemented in schools to promote life, health, sport and psychological skill training. The program should be used together with other community interventions as a health promotion strategy.

\section{REFERENCES}

ALLPORT, G.W. (1961). Pattern and growth in personality. New York, NY: Holt, Rinehart \& Winston.

BECK, A.T. (1976). Cognitive therapy and the emotional disorders. New York, NY: New York International Universities Press.

BIDDLE, S.; WANG, J.; CHATZISARAY, N. \& SPRAY, C.M. (2003). Motivation for physical activity in young people: entity and incremental beliefs about athletic ability. Journal of Sport Sciences, 21: 973-989.

BUHLER, C. (1935). The curve of life as studied in biographies. Journal of Applied Psychology, 19: 653-673.

BULL, S.; ALBINSON, J. \& SHAMBROOK, C. (1996). The mental game plan. Getting psyched for sport. Eastbourne: Sports Dynamics.

CARPENTER, W.B. (1894). Principles of mental physiology. New York, NY: Appleton.

DWECK, C.S. (1999). Self-theories: their role in motivation, personality and development. Philadelphia, PA: Taylor and Francis/Psychology Press.

DWECK, C.S. (2005). Self-theories: the mindset of a champion. Proceedings from the $11^{\text {th }}$ World Congress of Sport Psychology. August 15 to August 19, Sydney, Australia.

ELLIS, A. (1962). Reason and emotion in psychotherapy. New York, NY: Lyle Stuart.

ERIKSON, E. (1959). Identity and the life cycle. Psychological Issues, 1: 18-164.

HALL, C.R.; MACK, D.E.; PAIVIO, A. \& HAUSENBLAS, H.A. (1998). Imagery use by athletes: development of the sport imagery questionnaire. International Journal of Sport Psychology, 29: 73-89.

HANIN, Y.L. (1997). Emotions and athletic performance: individual zones of optimal functioning. European Yearbook of Sport Psychology, 2: 298-313. 
HARMISON, R.J. (2006). Peak performance in sport: identifying ideal performance states and developing athletes psychological skills [electronic version]. Professional Psychology: Research and Practice, 37: 233-243. Retrieved 10 May 2007 [http://search.global.epnet.com].

HARRIS, D.V. \& HARRIS, B.L. (1984). The athlete's guide to sport psychology: mental skills for physical people. Champaign, IL: Leisure Press.

HARWOOD, C.; CUMMING, J. \& FLETCHER, D. (2004). Motivational profiles and psychological skills use with within elite youth sport [electronic version]. Journal of Applied Sport Psychology, 16: 318-322. Retrieved 10 May 2007 [http://search.global.epnet.com].

JACOBSON, E. (1929). Progressive relaxation. Chicago, IL: University of Chicago Press.

JAHODA, M. (1958). Current concepts of positive mental health. New York, NY: Basic Books.

JENNINGS, K.E. (1993). Mind in sport. Directing energy flow into success. Ndabeni, Cape: The Rustics Press.

JUNG, C.G. (1933). Modern man in search of a soul (W.S. Dell \& C.F. Baynes, Trans.). New York, NY: Harcourt, Brace and World.

KIRSCHENBAUM, D.; McCANN, S.; MEYERS A. \& WILLIAMS, J. (1995). The use of sport psychology to improve sport performance [electronic version]. Sport Science Exchange, 6. Retrieved 15 July 2005

[http://www.gssiweb.com/reflib/refs/59/alt_0000000200000386.pdf?CFID=2024604\&CFTOKEN $=38810862$.

LANE, A.M.; HARWOOD, C. \& NEVILL, A.M. (2001). Confirmatory factor analysis of the thought occurrence questionnaire for sport (TOQS) among adolescent athletes [electronic version]. Anxiety, Stress, and Coping, 18: 254-244. Retrieved 10 May 2007 [http://search.global.epnet.com].

LANG, P.J. (1979). A bio-informational theory of emotional imagery. Psychophysiology, 17: 495-512.

LEVY, S.; STROESSNER, S. \& DWECK, C.S. (1998). Stereotype formation and endorsement: the role of implicit theories. Journal of Personality and Social Psychology, 74: 1421-1436.

MACDOUGALL, M.; SCOTT, D.; McFARLANE, G.; LEBLANC, J. \& CORMIER, T. (2001). Using a single subject multiple baseline design to evaluate the effectiveness of a mental skills package on basketball foul shooting, vol. 4 (105-107). Proceedings of the $10^{\text {th }}$ World Congress of Sport Psychology. May 28 to June 2, Skiathos Greece. Thessaloniki: Christodoulidi.

MARTENS, R.; VEALEY, R.S. \& BURTON, D. (1990). Competitive anxiety in sport. Champaign, IL: Human Kinetics.

MASLOW, A.H. (1968). Toward a psychology of being ( $2^{\text {nd }}$ ed.). New York, NY: Van Nostrand.

MEICHENBAUM, D. (1985). Stress inoculation training. New York, NY: Pergamon Press.

MORAN, A.P. (2004). Sport and exercise psychology: a critical introduction. London: Routledge.

MTHEMBU, S.T. (2001). Empowering unemployed people through self-help groups. $\mathrm{PhD}$ (Community Psychology) dissertation. KwaDlangezwa: University of Zululand.

NEUGARTEN, B.L. (1973). Personality change in later life: A developmental perspective. In C. Eisdorfer \& M.P. Lawton (Eds.), The psychology of adult development and aging (311-355). Washington, DC: American Psychological Association.

NIDEFFER, R. (1985). Athletes guide to mental training. Champaign, IL: Human Kinetics.

PIETERSE, J.J. \& POTGIETER, J.R. (2006). Die effek van sportsielkundige intervensietegnieke op die prestasie van middelafstand-atlete. South African Journal for Research in Sport, Physical Education and Recreation, 28(1): 85-89.

RAPPAPORT, J. (1985). The power of empowerment language. Social Policy, 53: 596-602.

ROBERTS, G.C.; TREASURE, D.C. \& BALAGUE, G. (1998). Achievement goals in sport: the development and validation of the Perception of Success Questionnaire [electronic version]. Journal of Sports Science, 16: 337-347. Retrieved 9 July 2005 [http://www.ncbi.nlm.gov/Pubmed]. 
ROGERS, C.R. (1961). On becoming a person. Boston, MA: Houghton Mifflin.

RYFF, C.D. (1989). Happiness is everything, or is it. Explorations on the meaning of psychological well-being. Journal of Personality and Social Psychology, 57: 1069-1081.

RYFF, C.D. \& KEYES, C.L.M. (1995). The structure of psychological well-being revisited. Journal of Personality and Social Psychology, 69: 719-727.

SACKET, R.S. (1934). The influences of symbolic rehearsal upon the retention of a maze habit. Journal of General Psychology, 13: 113-128.

SANCHEZ, X. \& LESYK, J.L. (2001). Mental skills training using the "nine mental skills of successful athletes" model, vol. 4 (85-86). Proceedings of the $10^{\text {th }}$ World Congress of Sport Psychology. May 28 to June 2, Skiathos Greece. Thessaloniki: Christodoulidi.

SHELDON, J. \& ECCLES, J. (2005). Physical and psychological predictors of perceived ability in adult male and female tennis players [electronic version]. Journal of Applied Sport Psychology, 17: 4863. Retrieved 10 May 2007 [http://search.global.epnet.com].

SNAUWAERT, E. (2001). A psychometric evaluation of Bull's mental skills questionnaire: a study on Flemish athletes, vol. 5 (23-25). Proceedings of the $10^{\text {th }}$ World Congress of Sport Psychology. May 28 to June 2, Skiathos Greece. Thessaloniki: Christodoulidi.

WANN, D. \& CHURCH, B. (1998). A method for enhancing the psychological skills of track and field athletes [electronic version]. Track coach, 114. Retrieved 17 May 2005 [www.coachr.org/psychskills.htm].

WATSON, N.J. \& NESTI, M. (2005). The role of spirituality in sport psychology consulting: an analysis and integrated view of literature [electronic version]. Journal of Applied Sport Psychology, 17: 228-239. Retrieved 10 May 2007 [http://search.global.epnet.com].

WEINBERG, R.S. \& GOULD, D. (2007). Foundations of sport and exercise psychology (4 ${ }^{\text {th }}$ ed.). Champaign, IL: Human Kinetics.

WISSING, M.P. \& VAN EEDEN, C. (1998). Psychological well-being: a fortigenic conceptualization and empirical clarification. In L. Schlebusch (Ed.), South Africa beyond transition: psychological well-being (379-393). Pretoria: Psychological Society of South Africa.

WITTON, G. (2004). Sport psychology. In L. Swartz; C. de la Rey \& N. Duncan (Eds.). Psychology: an introduction (385-403). Cape Town: Oxford University Press.

YERKES, R.M. \& DODSON, J.D. (1908). The relation of strength of stimulus to rapidity of habit formation. Journal of Comparative and Neurological Psychology, 18: 459-482.

Prof. D.J. Edwards: 3 Antigua, 32 Chartwell Drive, Umhlanga Rocks 4319, Republic of South Africa. Email: sdedward@ telkomsa.net 